\title{
ROSALÍA DE CASTRO: NO PRINCIPIO FOI A TRADUCIÓN
}

Áurea Fernández Rodríguez

Universidade de Vigo

doi: 10.17075/rcsxxi.2014.37

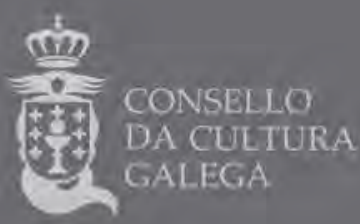





\section{INTRODUCIÓN}

As investigadoras que traballan na Biblioteca da Tradución Galega (BITRAGA) ${ }^{1}$ dende o ano 2004 pretenden presentarlle ao usuario unha ferramenta práctica que recolla as traducións dende o galego e cara ao galego en formato libro. Trátase de ofrecer unha visión global e crítica da relación do campo literario galego con outros campos e culturas. $\mathrm{Na}$ actualidade, a base pon a disposición do usuario as traducións de obras literarias dende e cara ao galego, e aínda que de momento só están accesibles as obras en formato libro a partir de 1980, xa se está a traballar na segunda fase do proxecto que inclúe a etapa anterior e outros soportes e formatos como as publicacións periódicas. Ademais de diferenciar linguas e espazos culturais, BITRAGA ten a particularidade de vincular a ficha da obra orixinal coas súas traducións para visibilizar os diferentes actores do proceso comunicativo, especialmente as tradutoras e tradutores (Vid. Galanes 2012: 87-108).

Ademais da tradución dalgunhas obras completas de Rosalía de Castro que se poden localizar tanto polo título do seu orixinal, polo da súa tradución como pola autora, dispońemos de volumes que recollen os poemas traducidos espallados en antoloxías que, por ser froito dunha selección moi persoal daquel que realiza a escolla, o usuario deberá buscar por editor ou título da obra. Por exemplo, o volume que se titula Poesías na tradución ao portugués brasileiro (po BR) de Ecléa Bosi pode buscarse pola autora da obra orixinal, pola tradutora e polo título. Os interesados contan, ademais, con información adicional sobre os paratextos ou a composición do volume ${ }^{2}$. O libro monolingüe en portugués (po BR) remata cun capítulo titulado «Homenagem da editora» (Editora Nós, Publicaçôes Galicia Ceibe), onde se inclúen os poemas traducidos de Federico García Lorca "Ergue-te, minha amiga...» (Bosi 1966: 119) e o que compuxo especialmente Curros Enríquez para o traslado dos restos da poeta á igrexa de San Domingos de Bonaval (Santiago de Compostela). A pequena antoloxía, con prólogo de Guil-

1 http://www.bibliotraducion.uvigo.es

2 Para máis infomación sobre a funcionalidade da base, véxase Montero Küpper (2010). 
herme Almeida titulado "Galicia patria da canção», introduce na cultura brasileira unha selección de poemas de Follas novas: «Leva-me àquela fonte cristalina», «Maio longo», «Enquanto o gêlo as recobre», «Quando era tempo de inverno», "Quando penso que te fôste», «Em Cornes», etc.

O tradutor é un elo fundamental na importación e na exportación do libro e, polo tanto, da cultura, pero o seu traballo aínda hoxe non ten o recońecemento que se merece. Por este motivo, damos protagonismo no noso traballo ás tradutoras e tradutores, á vez iniciadores e axentes, que verteron e levaron polo mundo adiante a obra de Rosalía de Castro. Pretendemos deseñar un mapa de tradutores que, ao manter algunha conexión entre eles, permiten construír unha rede (actor-rede). Queremos demostrar, ademais, que o éxito da poesía de Rosalía de Castro pasa, sobre todo, por criterios de calidade máis que por gustos persoais dos propios actores. Isto pode parecer obvio, pero para aqueles que utilizan unha lingua ponte ou que pretenden chegar a outras culturas a través dunha lingua franca non o é tanto.

Para achegármonos ao tema cunha óptica científica empregamos o concepto de actor-rede na lińa da teoría dos sociólogos Michel Callon e Bruno Latour (1991). En síntese, esta teoría propón a noción de «actor rede» ou de «rede intelectual» como unha ferramenta mnemotécnica que nos axuda a observar a $(s)$ traxectoria(s), a posición e as relacións entre os actores e/ou axentes dun determinado campo ou de varios campos literarios. Recupérase, tamén, a concepción de "campo" da socioloxía de Pierre Bourdieu (1998), pero tendo en conta que, como xa se deixou bastante claro noutro estudo, se presta a diferentes interpretacións en función da perspectiva que adoptemos (Fernández 2010: 48). Neste caso, insistimos, non avaliamos o resultado das traducións nin o proceso no seu conxunto, senón o subcampo dos tradutores dentro dese proceso.

Hai numerosos iniciadores, á vez tradutoras e tradutores, que abriron novos mercados ou que lograron achegar a outros campos literarios a obra en galego de Rosalía de Castro, sobre todo no contexto democrático, «no que a literatura galega, e dentro dela a poesía que sempre estivo na súa vangarda, conseguiu estabilizar un verdadeiro sistema literario» (Villanueva 1999: 8). A primeira clasificación faise atendendo aos principais mercados que dialogan co campo literario galego: mundo hispano, mundo anglófono e, baixo o apartado doutros mercados, inclúense varios proxectos: por unha parte, o xaponés e o ruso, ambos os dous 
difundidos por vía académica con resultados moi positivos; pola outra, a cultura xermánica e o ámbito francófono, nos que Rosalía de Castro apenas tivo eco.

\section{MUNDO HISPANO}

\section{I.1. No principio foi a tradución}

Sabemos que a nosa autora, ademais de poeta en galego, exerceu a actividade da tradución nas dúas combinacións castelán-galego e galego-castelán. Autotraduciuse para deixarnos as versións en castelán de «iNin as escuras!», «A xusticia pola man» e "Tembra a que unha inmensa dicha...", as tres composicións de Follas novas. Esta última foi publicada no xornal decenal de Bos Aires que dirixía Manuel Castro López, El Eco de Galicia (20/05/1897). As primeiras traducións de Rosalía de Castro publicáronse en 1863 e queremos pensar que mesmo empezou a traducir antes que crear no idioma de Galicia. De aí o subtítulo deste apartado, «No principio foi a tradución», inspirado na exposición titulada «No principio foi o verso» que se exhibiu en Vigo (15-05-2013 ao 15-08-2013); e que recuperamos no título do presente texto. Cómpre abordar, polo tanto, a tradución en Rosalía de Castro no mundo hispano dende unha perspectiva dupla: a autora como tradutora e a autora traducida.

A primeira tradución da que temos constancia dos versos de Cantares gallegos aparece en El Museo Universal ${ }^{3}$, no ano 1864. Trátase duns versos ao castelán que insire o poeta Ventura Ruiz Aguilera (1820-1881) nun artigo en dúas entregas sobre o libro Cantares gallegos publicado en Vigo en 1863 na imprenta de Juan Compañel. Uns anos antes, no mencionado xornal literario madrileño, o poeta salmantino, moi próximo a Manuel Murguía e a Rosalía de Castro, dedícalle «La gaita gallega. Eco nacional. A mi querido amigo don Manuel Murguía» (Ruiz Aguilera 1860: 382-383). O romance foi traducido por Rosalía de Castro ao galego e publicado por primeira vez na edición príncipe de Cantares gallegos (Castro 1863: 135-139) baixo o título: «A gaita gallega. Resposta ao eminente poeta

3 Este xornal literario de carácter enciclopédico quincenal ata 1860 e logo semanal difundía artigos de historia, viaxes, arqueoloxía, ciencia e literatura. Publicábanse traducións de obras de George Sand, Chateaubriand ou do poeta alemán Heinrich Heine que lía Rosalía de Castro, segundo escribe Manuel Murguía en 1917 (Pociña, 1991: 490). 
D. Ventura Ruíz de Aguilera». Aínda que non hai constancia documental que o acredite, resulta moi probable que Castro traducise o poema despois da súa publicación e que espertase nela a conciencia reivindicativa galeguista ou, polo menos, que a reforzase. Pois o que se considera o seu primeiro poema en galego (López \& Pociña 1991: 123-125) foi publicado un ano despois en El Museo Universal. Falamos de «Adios, qu'eu voume» (24-XI-1861, p. 375) tares con algúns retoques, faltando unha estrofa 5 e engadindo a que comeza polo verso «Adiós ríos, adiós fontes».

Para apoiar a nosa tese, contamos con algún argumento máis, posto que a tradución é o camiño que emprenderon moitos dos mellores escritores antes de publicar as súas creacións orixinais. Uns anos antes, outro dos máximos expoñentes do Romanticismo español, Mariano José de Larra (1809-1837), cuxas obras contribuíron ao rexurdimento das aspiracións rexionais, xa presentaba a tradución como «una necesidad para todo aquel que quiere iniciarse en la literatura y en la escritura» (Larra 1981: 33).

En calquera caso, o resultado que conseguiu Rosalía de Castro convenceu totalmente ao autor traducido que, no citado artigo, loa a tradución con estas palabras: «La traducción, un poco glosada, de mi Eco nacional, La gaita gallega me satisface plenamente; el mayor elogio que de ella puedo hacer, es decir, que no la hubiera yo deseado mejor» (Ruiz Aguilera 1864: 183). Este non será o único eloxio que reciba Rosalía de Castro polas súas traducións, consideradas «infidèles» pero «belles».

Dende os primeiros anos da democracia ${ }^{6,}$ empézase a sentir a necesidade de revisar a obra de Rosalía de Castro para darlle unha visión distinta daquela que se viña ofrecendo na etapa da ditadura, na que se incluía a autora de Cantares galle-

4 Publicouse no mes de novembro de 1861 -e non no mes de setembro, como se afirma nalgúns traballos.

5 Foi eliminada a estrofa que di: «Por xiadas, por calores / Desde qu’amañece ó día / Dou á Terra os meus sudores / Mais canto esa Terra cria/Todo...todo é dos señores» (Castro 1861: 375).

6 Queda pendente o estudo das traducións de Rosalía de Castro na diáspora en América, na que tamén contamos con obras de referencia como a primeira tradución ao español da cubana Emilia Bernal, a de Germán Berdiales ou a tradución ao portugués de Ecléa Bosi, publicadas en 1958, 1953 e 1966 respectivamente. Aínda que só saíu á luz en 1958, Emilia Bernal afirma que traduciu os poemas en Madrid no ano 1928 (1958: 36-37). 
gos e Follas novas sempre dentro da literatura rexional ${ }^{7}$. Estas novas perspectivas democráticas e o avance das ideas favoreceron a introdución de novas análises como a da crítica feminista. Destacan, de maneira especial, sobre todo, pola repercusión que tiveron dentro e fóra de España as traducións de dous tradutores de recońecido prestixio: o escritor, xornalista e crítico teatral Mauro Armiño (1944-), premio á mellor tradución da crítica pola súa obra Poesías (1979) de Rosalía de Castro; e o poeta, ensaísta e cofundador de Abada Editores, Juan Barja.

Mauro Armiño sinala, na introdución do citado volume de Poesías, que a obra de Rosalía de Castro sufriu varios «desvíos» por parte dos lectores e dos historiadores das literaturas galega e castelá que a danaron gravemente: a sacralización simbólica da obra, o rexeitamento por parte dos historiadores da literatura galega de encadear Follas novas e En las orillas del Sar, e, finalmente, a clasificación dos historiadores da literatura castelá que a incluían «como figurón secundario tras Bécquer» (Armiño 1979: 17). Armiño tivo en conta versións de tradutores anteriores pero, contrariamente a eles (Basilio Losada, Xesús Alonso Montero ou Benito Varela Jácome), opta pola tradución en verso e mesmo altera a orde dalgúns poemas de Cantares. Pecha a súa antoloxía cos prólogos de Cantares gallegos e Follas novas.

Pola súa parte, Juan Barja edita as versións de Cantares gallegos (1985) e de Follas novas=Hojas nuevas (1985) o ano da conmemoración do centenario da morte da autora. O tradutor presenta Cantares gallegos como unha «obra de capital importancia en el ámbito de nuestra poesía» (Barja 1985: 5) e Follas novas como un dos «textos más prestigiosos de nuestro romanticismo -y digo nuestro reafirmándome en la más amplia concepción de nuestra cultura» (Barja 1985: 9). $\mathrm{Na}$ edición Follas novas=Hojas nuevas inclúe as traducións de Rosalía de Castro de «Ruinas» e "Cantares», na que respecta a versión orixinal en castelán do citado poeta salmantino. Porén, non menciona as traducións de Juan Ramón Jiménez

7 Nas enciclopedias e obras de referencia de literatura, os dous máximos representantes do Romanticismo español adoitaban ser Carolina Coronado e Gustavo Adolfo Bécquer. Ruiz Peña escribe no artigo titulado «Rosalía de Castro: 1937» (en Cauces 11-12 [1937] 10-11): «Pero aún no se le ha hecho la debida justicia; ante todo, Rosalía de Castro no es un poeta regional, sino español, universal» (Pociña, 1991: 682 e 691). Pola súa parte, Ecléa Bosi acode a algúns estudosos para lembrar a indiferenza da crítica ante Rosalía de Castro: «Sister Mary Pierre Tirrel pregúntase: Que se passa com Rosalía?, [...]. E Azorín: "Causa assombro a estulta incompreensão da crítica espanhola moderna de um dos mais originais poetas que a Espanha produziu"” (Bosi 1966: 26). 
(1881-1958) como o fai Mauro Armiño en Poesía (1979), onde confesa ter en conta para algún "poema concreto, las [versións] de la propia Rosalía y la de Juan Ramón del poema "Cando penso que te fuches", aunque he preferido la mía de "Este vaise" a la del autor de Espacio». (Armińo 1979: 22). Efectivamente, cómpre saber que as primeiras versións ao castelán dos poemas de Follas novas foron, sen dúbida, os fragmentos mencionados de "Pra a Habana» e "Negra sombra» ${ }^{8}$, que Juan Ramón Jiménez traduciu en 1896 cando só contaba quince anos de idade. Segundo algúns, atopou Follas novas no Ateneo de Sevilla (Sánchez 1986: 214) e, segundo explica Xerardo Álvarez Gallego en Galicia Emigrante, foi precisamente cando se atopaba en Moguer onde atopou o libro Follas novas, «en la biblioteca de un viejo señor republicano que era fanático de Castelar» (Álvarez 1957: 10). O certo é que «uno de los primeros ejercicios literarios de Juan Ramón Jiménez fue traducir a Curros Enríquez y a Rosalía de Castro» (Álvarez 1957: 10).

Juan Barja volve ao mercado no ano 2009 cunha nova edición revisada das poesías completas de Rosalía de Castro, prologada por Arturo Leyte, que dende a súa perspectiva filosófica tamén fai fincapé nesa interpretación da poética de Rosalía de Castro en termos monumentais máis que documentais e na necesidade dunha lectura aberta: «El problema de su lectura, en definitiva, no estriba en su texto original, sino en una cambiante difícil recepción» (Leyte 2009: 20). Barja revisa a tradución de 1985, pero mantén os mesmos criterios de tradución. Traduce como poeta para que os lectores que descońecen o idioma galego poidan acceder a estas obras. Explica que a metodoloxía que Rosalía de Castro adoptou como tradutora lle marcou o camiño e a orientación que tiña que seguir: «Rosalía fue una excelente traductora, más excelente cuanto más libre y, ¿sorprendentemente?, cuanto más libre mucho más fiel» (Barja, 1985: 9 e 2009: 25). Despois de darnos algunhas das escollas dos poemas de Ruiz de Aguilera vertidos ao galego, engade:

$Y$ es que el poeta tiene la mayor consideración, pero también la mayor indiferencia, por lo que a los filólogos atańe $[. .$.

8 O poema musicado «Negra sombra», un dos máis emblemáticos da música galega, foi presentado por primeira vez no Gran Teatro da Habana no ano 1892. Tanto o poeta andaluz como todos os intelectuais da última década do século xix estaban ben atentos ao espírito independentista de Cuba, que culmina coa insurrección de 1895 contra a coroa española. Ademais, Curros Enríquez foi un gran difusor de Rosalía de Castro en Cuba e fundou a revista Follas Novas (1896-1909). 
Mas no se asuste el lector. Respetuoso y tímido como soy, en nigún caso creo haber llegado a tales — y tan abundantes — transformaciones. He querido seguir la orientación — dije de dichas traducciones, pero no el mismo camino. Me decidí así por la versión rítmica y rimada, siguiendo los modelos originales tal como creo que le hubiera gustado a Rosalía, mas tratando de guardar al máximo la semejanza, aun a riesgo de afear el resultado, sustituyendo, supliendo, variando en contadísimas ocasiones «lo que dice» el poeta, para respetar mejor lo que el poeta canta. Además, siendo esta edición bilingüe — como quizá siempre deberían ser, al menos las de todas las traducciones de libros de poesía-, la insuficiencia de mis logros queda más que favorablemente saldada y corregida. La versión castellana es así el trampolín donde se podrán apoyar los que no alcancen a desenvolverse directa o indirectamente en gallego. (Barja 1985: 10 e 2009: 26).

\section{MUNDO ANGLÓFONO (1909-2013)}

Ademais, o castelán serviu de lingua ponte para difundir a obra de Rosalía de Castro e a literatura galega fóra das nosas fronteiras, especialmente á lingua franca, ao inglés, pero non só. Aínda que os primeiros versos en inglés son os do poema de Follas novas, «Unha vez tiven un cravo...» (1909), a primeira antoloxía preparada para lectores de fala inglesa foi Oxford Book of Spanish Verse, compilada por James Eitzmaurice Kelly, que viu a luz no ano 1913. Segundo a monxa, escritora irlandesa, tradutora9 e estudosa da obra de Rosalía de Castro Miss Perry, «A partir de entonces, la obra lírica de la autora de Follas Novas ha adquirido en Inglaterra una interesante difusión, y son ya varios los estudios que en nuestro idioma se han consagrado al gran poeta gallego» (Barreiros 1955: 40).

No entanto, a única antoloxía neses anos na que se ten constancia de traducións da autora que nos ocupa foi Poems, publicada en 1964 e impulsada dende a cultura de partida. Aínda que o lector poderá atopar un estudo máis completo sobre as traducións ao inglés en Fernández et alii (2011: 70-81), nas comunicacións de Jonathan Dunne e Olga Castro nestas mesmas actas, queremos destacar que as traducións se fixeron esperar ata as dúas últimas décadas e, á falta dun estu-

9 "Ahora está preparando un libro sobre nuestro gran poeta, junto con una traducción de sus obras, con destino a las universidades inglesas» (Barreiros 1955: 6). 
do da súa distribución e recepción, con perspectiva temporal podemos adiantar que o resultado non é aínda moi frutífero. Pois se exceptuamos Galician Songs (2013) na tradución de Erín Moure, só se poden citar antoloxías que responden aos gustos de contados mediadores: Poems (1991); a antoloxía The Poetry and Prose of Rosalia de Castro: A Bilingual Facing Page Edition, de John e Aileen Dever (2010); a antoloxía de Antonio de Toro (ed.), Breogán's Lighthouse: An Anthology of Galician Literature; a de Jonathan Dunne (ed.), Anthology of Galician Literature 1981-1911; Antoloxía da literatura galega (2010), Xunta de Galicia/Xerais/ Galaxia, logo financiada pola cultura de partida coa intención de empregala como ponte para acceder a outras culturas. A consideración deste idioma como lingua franca por parte dos axentes da cultura galega favorece esa posición privilexiada do inglés como lingua mediadora.

Hai algún intento de saír da vía institucional e académica para conseguir un oco no circuíto comercial, como é o caso de Selected Poems (2007). Trátase dunha selección de poemas de Cantares gallegos e Follas novas que o poeta irlandés Michael Smith (Dublín 1942-) verteu desde a versión galega e a castelá. Ao descoñecer a lingua galega tivo que contar coa axuda de dous profesores: José Manuel Estévez Saá, profesor de Filoloxía Inglesa na Universidade da Coruña, e Margarita Estévez Saa, tamén profesora de Filoloxía Inglesa da Universidade de Santiago de Compostela. Estamos ante un tradutor de recońecido prestixio que conta no seu haber con numerosas traducións de autores da poesía española (Gerardo Diego, César Vallejo ou Gustavo Adolfo Bécquer) e mexicana (Elsa Cross) que buscan visibilidade internacional mediante a tradución cara á lingua franca, publicadas en Shearsman Books ${ }^{10}$. Esta pequena empresa especializada en poesía sorprende cun repertorio de traducións moi variado ${ }^{11}$ da poesía clásica ou contemporánea do francés, turco, noruegués, chinés, sueco, ruso, alemán, etc. $\mathrm{O}$

10 Ademais desta selección de Cantares e Follas novas (2007), saíron co selo desta empresa tres libros da poesía de Chus Pato traducidos por Erín Moure: Charenton (2007), m-Talá (2009) e Hordes of Writing (2011); de María do Cebreiro: I am not from here (2010) [Trad. Helena Miguélez-Carballeira] e Forked tongues, editada por Manuela Palacios (2011). A data de falecemento de Rosalía de Castro aparece trabucada na páxina web da editorial: http://www.shearsman.com/pages/books/catalog/2007/castro.html [última consulta 16-05-2013].

11 http://www.shearsman.com/pages/books/catalog/translations.html. 
que dá unha idea do tipo de culturas e autores polos que manifesta interese ${ }^{12}$. $\mathrm{O}$ catálogo das traducións desta editorial parece que non se limita a presentar literaturas estranxeiras a un público irlandés, senón que pretende chegar ata un lector potencial noutros países anglófonos: Reino Unido ou Australia, na que máis dun $9 \%$ da súa poboación son de descendencia irlandesa. Tamén abre portas cara a outras culturas que buscan rarezas para ofrecérllelas aos seus lectores máis selectos $^{13}$. Para captar o lector, o editor presenta a autora como poeta revolucionaria nas dúas linguas, a galega e a castelá (a lingua franca) por dous motivos esenciais: no campo literario español, desempeña o papel de precursora da poesía española (moderna) do século xx e unha das máximas figuras ao carón de grandes nomes como García Lorca ou Cernuda; no campo literario galego, é a iniciadora da poesía moderna en galego. Destácase, polo tanto, que se está a difundir a obra dunha figura de referencia para todos aqueles que desexan cońecer a literatura española e mesmo a literatura hispana porque sen a española tampouco se entenderían as literaturas hispanoamericanas.

\section{OUTROS MERCADOS}

\section{III.1. A cultura xaponesa}

Aínda que temos traducións a moitas linguas, nos mercados emerxentes a presenza de Rosalía de Castro é practicamente nula. Mais temos Cantares gallegos na versión xaponesa do profesor Takekazu Asaka, con limiar do presidente da Real Academia Galega, Xesús Alonso Montero, e introdución do tradutor. Takekazu Asaka entrou en contacto coa cultura galega no ano 1978 cando se atopaba nun curso de doutoramento en Madrid. Dende a súa primeira visita a Galicia en 1989, publica varios traballos sobre a lingua e a literatura galegas con títulos como: Gramática do galego moderno (1993), Gramática de conversación en galego (1994) e Vocabulario básico da lingua galega (1996). Asaka non deixou de traballar por difundir a lingua e a cultura galegas. Ademais destes estudos, traduciu os

12 A páxina da editorial conta cun enlace ao Pórtico de Literatura galega:

http://galicianliterature.com/translation-grants.

13 Mais as escasas vendas denotan pouco interese do público anglófono (aproxim. 100 exemplares). 
nosos clásicos. No volume Canta a Ramón Cabanillas. A ti, meu Cambados, con introdución de Francisco Fernández Rei, «incluye 17 poemas de Cabanillas en japonés y en gallego» (Luna 2012: 159).

En 1993, dá a coñecer nunha revista xaponesa os «Seis poemas galegos» que Federico García Lorca (1898-1936) adulto escribiu en Santiago (1935). O poeta granadino, como sabemos, é un autor de referencia na literatura española, ao que lle debeu afectar moi fondamente a poesía de Rosalía de Castro e a paisaxe de Galicia desde a súa primeira visita en 1916, cando contaba con 18 anos de idade. Ao vincular os dous poetas, Takekazu Asaka fai proba de coñecer a afinidade entre eles e a intención de introducir a literatura galega no lector xaponés a través dun autor internacional da literatura española como Federico García Lorca. No ano 2002, xa se podían ler 21 poemas de Cantares gallegos no idioma xaponés. Nunha nova edición (2009), non só engade 8 poemas máis, senón que revisa os anteriores, e dáse así case a totalidade dos Cantares gallegos. Esta última edición inclúe ademais un CD de poemas musicados. A obra de Rosalía de Castro, traducida directamente do galego e publicada pola editora DTP Publishing de Tokyo, chegou así á cultura xaponesa por vía académica, mais a súa difusión foi totalmente planificada. Isto amosa a relevancia do papel que está a desempeńar o «labor de investigación e sistematización histórico-crítica» (Villanueva 1999: 10) nas universidades e na rede de centros académicos, especialmente nos centros de estudos galegos.

\section{2. A cultura rusa}

Outra boa proba témola no Centro de Estudos Galegos de San Petersburgo, onde Elena Zernova soubo espertar o interese dos lectores rusos. Pois como apunta a propia tradutora e editora de varios volumes, "Aínda que as primeiras indicacións sobre a existencia das obras literarias» en lingua galega «as encontramos nalgunhas publicacións da fin do século XIx, foi soamente na época recente cando a literatura galega comezou a facerse coñecida e apreciada en Rusia» (Zernova 2008: 257). Curiosamente, coma no caso xaponés, a primeira tradución rusa da poesía escrita en galego no século pasado foron os citados Seis poemas galegos publicados en 1960 no poemario Lírica escollida de Federico García Lorca, vertidos a través do castelán. 
As obras de Rosalía de Castro aparecen, por primeira vez, en 1977, en dúas antoloxías poéticas tituladas Poesías de Europa en tres volumes e Poesía europea do século XIX. Trátase de "dous fragmentos do poema "Campanas de Bastabales", dous Cantares gallegos e uns poemas escritos en castelán» (Zernova 2008: 258). Mais o «verdadeiro descubrimento do fenómeno literario galego comeza» (Zernova 2008: 258) en 1994 grazas á creación do Centro de Estudos Galegos na Universidade de San Petersburgo pola Dirección Xeral de Política Lingüística da Consellería de Educación e Ordenación Universitaria da Xunta de Galicia pouco despois de que Alfredo Conde deixara o seu cargo de deputado no Parlamento de Galicia como independente no grupo PSdeG (1981-1993).

Os primeiros tradutores, que eran poetas rusos, descoñecían o idioma galego. En 1996, o segundo volume da serie Entre dous silencios está dedicado á poesía do século XIX ata o primeiro terzo do Xx: «Abrangue a poesía do rexurdimento, comezando coa obra de Rosalía e terminando cos Seis poemas galegos de Lorca» (Zernova, 2008: 258). Aquí Rosalía de Castro convive, literariamente falando, con outros dezaseis poetas que están representados por máis de cen poemas. Aínda que tardou en chegar, a obra en galego de Rosalía de Castro, como escribe Xesús Alonso Montero, no prólogo da edición rusa do citado tomo X:

Chega agora, 120 anos despois da súa morte, e chega moi ben representada (como poeta en idioma galego) na escolma feita por Elena Golubeva e coordinada pola profesora Elena Zernova, que é, desde 1993, a embaixadora da literatura galega en Rusia, a gran introdutora. [...] a gran singradura da poesía de Rosalía de Castro na patria de Pushkin, Esenin, Maiakovski e Pasternak empeza hoxe. (Alonso 2005: 31).

$\mathrm{Na}$ actualidade, o lector ruso dispón non só dun panorama histórico da literatura galega, senón que xa pode ler na súa lingua os nosos escritores en volumes individuais. Como non podía ser doutro xeito, o tomo $\mathrm{X}$, que inaugura no ano 2005 esa nova andaina, titúlase Rosalía de Castro publicado en edición bilingüe (galego-ruso). Esta vez o prólogo, os 12 poemas de Cantares gallegos (2005: 32-108), así como os 28 poemas e o prólogo de Follas novas (2005: 110 a 181) tradúcense directamente ao ruso dende o galego, segundo afirma a encargada da edición, Elena Zernova: «Todas as traducións as fixeron especialmente para a antoloxía poetas e tradutores rusos, que, traballando xuntos, procuraron (e logra- 
ron) conservar tanto a estrutura rítmica como a rima auténtica do verso, de modo que os poemas soan en ruso moi próximos ó orixinal» (Zernova 2008: 259).

Aínda que o noso obxectivo está fixado nos tradutores, cómpre destacar, tamén, neste labor de introdución da literatura galega na cultura rusa a mediación doutros axentes que interveñen na rede do proceso. Prestixiosas editoriais, como é o caso da editorial Nauka, os prologuistas, cońecidos especialistas da literatura galega (Xesús Alonso Montero, Basilio Losada, Anxo Tarrío, Darío Villanueva, etc.) e o apoio institucional a través do Centro de Estudos Galegos da Universidade de San Petersburgo son valores engadidos que impulsan o proxecto e que sen eles probablemente non tería continuidade. O labor deste Centro de Estudos destaca, ademais, polas súas colaboracións con outras institucións como a Unión de Escritores de Rusia, Sociedade Literaria, Sociedade Folclórica, etc.

\section{III.3. A cultura xermánica}

En Alemaña, en 1913, os escritores C. Viktor E. Björkman e a súa dona, a poeta Marie Björkman-Schlikau, publicaron a tradución ao alemán de «Negra sombra» e as composicións que empezan "No ceo azul, crarísimo...", "Maio longo... maio longo» (López \& Pocińa 1991: 446). Considéranse os primeiros versos traducidos ao alemán e ao longo destes anos non temos traducións representativas nesta lingua. Só podemos mencionar na antoloxía bilingüe de Marga Romero e Dieter Kremer, 20 Gedichte aus Galicien (2007), a versión alemá de Nuno Oliveira do poema de «Negra sombra», "Cando penso que te fuches» (Romero 2007: 19).

Como non contamos aínda nin con antoloxías representativas nin con obras completas de Rosalía de Castro traducidas ao alemán, Javier Gómez Montero está a traballar para encher ese baleiro.

\section{III.4. A cultura francesa}

Cabe lembrar tamén a Anthologie poétique (2002), non pola repercusión que tivo, senón máis ben pola indiferenza que lle está a manifestar a cultura francesa á obra de Rosalía de Castro. Esta antoloxía naceu da man do tamén poeta José Carlos González, editada por Les Presses Universitaires de Rennes e Éditions Folle Avoine. Varios profesores do Comité Bretagne-Galice participaron no proxecto para facelo realidade, despois da morte repentina do tradutor, que lle impediu 
facer os últimos retoques á súa versión. Na nota biográfica da autora, Robert Omnès deixa patente a necesidade de ter en conta o legado da lírica de Rosalía de Castro, pois preséntaa dentro da tradición bárdica como os poetas galegos da Idade Media. A súa poesía, cunha forte influencia da temática romántica, imprime, no entanto, unha marca moi persoal:

De xeito moi "progresista», protesta contra o destino que a sociedade burguesa lle dispensaba á muller. Unha burguesía que toleraba mal as literatas como Rosalía de Castro. Manifesta a súa indignación polo destino do pobo galego, condenado pola miseria a emigrar a América e vítima do xenocidio cultural

Expresa, finalmente, a súa angustia metafísica, o seu mal existencial e a súa "dor de vivir» (Robert Omnès 2002: 8) ${ }^{14}$.

Malia que o tradutor non puido facer a última revisión e que imprime a súa versión con algunhas «belles infidèles», a tradución en verso está bastante ben lograda. Permítese algunha liberdade para escapar do sentido literal, pero permanece fiel ao espírito dos poemas. Hai que lamentar que un país como Francia, privilexiado pola súa literatura e que se preza de ser o que máis traduce, descońece case por completo a obra de Rosalía de Castro.

A última Xornada da Tradución, que se realizou un ano máis no marco da Feira do Libro de París 2013, centrouse nas funcións, as modalidades e as dificultades actuais da tradución, especialmente a través do papel de mediador do tradutor, a cuestión dixital e as dificultades específicas das linguas raras. $\mathrm{O}$ tema dunha das mesas, "Traducir alén das fronteiras», partía da idea de que as "xoias» da literatura estranxeira están, en ocasións, ocultas en países pouco explorados, á marxe das redes oficiais ou ben en xéneros pouco actuais. E os tradutores son, a miúdo, os mellores á hora de dalas a coñecer e os mellores embaixadores dos seus autores ${ }^{15}$. Pois ben, a literatura catalá e a romanesa, as dúas invitadas de honor, foron as beneficiarias da promoción das súas obras, dos seus autores e da súa literatura.

14 A tradución é nosa.

$15 \mathrm{http} / /$ www.salondulivreparis.com/PRO/Les-Rencontres-de-la-traduction.htm [última consulta 27-05-

2013, a tradución do resumo do programa é nosa]. Romanía foi o único país que se presentou a concurso, o que denota certa falta de interese para potenciar a cultura propia. 


\section{CONCLUSIÓNS}

$\mathrm{Na}$ era dixital e da globalización, contamos con diferentes traducións da obra galega de Rosalía de Castro a moitas linguas: alemán, árabe, bengalí, catalán, chinés, éuscaro, francés, inglés, portugués, etcétera; pero poucas son as versións das dúas obras completas que escribiu en galego e mesmo en castelán. En termos cuantitativos, tampouco son moitos os poemas traducidos. Cómpre destacar, igualmente, que os tradutores son xeralmente actores que gozan dun notable prestixio dentro do campo literario de chegada e buscan traducións con marca de calidade para anotalas como elemento diferenciador no seu haber. Mais non todos dominan o galego, polo que se ven obrigados a partir das versións en castelán. Este é o caso dos poetas Michael Smith ou de John Howard Reid. Este último está precisamente a preparar a versión dun terceiro volume de traducións da obra de Rosalía de Castro baseado na versión castelá de Mauro Armiño. Que quere dicir isto? Que existen traducións en castelán que impulsan a difusión da literatura galega, pero, ao mesmo tempo, hai que lamentar que teñamos que pagar esa peaxe para traspasar fronteiras.

Quedan aínda moitos campos, especialmente os dos mercados emerxentes, que non descubriron aínda a nosa musa na súa xusta medida. Pois a cultura de partida ten o deber de presentarlle ao lector de fóra unha visión unitaria da obra poética de Rosalía de Castro porque se trata dunha creación de capital importancia non só para a literatura galega, senón tamén para a castelá «y de notorio influjo en la lírica del siglo xx: en especial entre los poetas “exquisitos” paradójicamente: Juan Ramón Jiménez, Luis Pimentel» (Armiño 1979: 18). Xesús Alonso Montero (1997) e Arturo Leyte (2009: 22-24) engaden aínda outros clásicos, como Azorín, Unamuno, Gerardo Diego ou Cernuda, que consideran imprescindible a lírica de Rosalía de Castro no mapa da literatura universal. A colaboración de actores da cultura de partida e de chegada realmente comprometidos para lograr mellores resultados é a que está a conseguir maior froito, pero hai que ter en conta que a irrupción da obra de Rosalía de Castro e de calquera outra obra debe evitar pasar por unha lingua mediadora. Unha lingua e unha cultura mediatizadas dificilmente conseguirán unha internacionalización efectiva e duradeira. Cómpre, ademais, unha estratexia de difusión axeitada para que tanto a nosa autora auroral como calquera outro escritor galego non permanezan fosilizados en obras que non lograron chegar ao último elo da cadea, é dicir, ao lector. 


\section{REFERENCIAS BIBLIOGRÁFICAS}

Alonso Montero, Xesús (2005): «Prólogo», en Elena Zernova (ed.), Rosalía de Castro, San Petersburgo, Centro de Estudos Galegos da Universidade de San Petersburgo, X, 1-31.

Álvarez Gallego, Xerardo (I957): «Juan Ramón e Rosalía», Galicia Emigrante, 27, ano IV, marzo-abril, $10-11$.

Barreiros, Cosme (1955): «Rosalía de Castro, vista por una escritora inglesa», Galicia Emigrante, 12, ano II, xuño-xullo, 6 e 40.

Bourdieu, Pierre (1998): Les règles de l'art. Genèse et structure du champ littéraire, París, Éditions du Seuil.

Callon, Michel / Bruno Latour (I99I): La science telle quelle se fait. Anthologie de la sociologie des sciences de langue anglaise, París, Éditions La Découverte.

Castro, Rosalía de (1861): «iAdiós qu’eu voume!», El Museo Universal, 47, ano V, 24/XI/1861, 375.

Castro, Rosalía de (1897): "Tiembla que una inmensa dicha...», El Eco de Galicia, 201 (20/V/1897), 5. Dispoñible en (http://www.galiciana.bibliotecadegalicia.xunta.es/es/consulta/registro.cmd?id=3867) [última consulta: 28/05/2013].

Castro, Rosalía de (1953): Intimas. [Selección e trad. de poemas de Rosalía de Castro do galego ao español de Germán Berdiales]. Bos Aires, Hachette.

Castro, Rosalía (1958): Saudades. Poesías. Ensayo y traducción de Emilia Bernal, Santiago de Chile, Editorial Nascimento.

Castro, Rosalía de (1964): Poems. [Translated from the Galician by Charles David Ley. Introduction and Selection by J. Filgueira-Valverde]. Madrid, Ministry of Foreign Affairs.

Castro, Rosalía de (1966): Poesías. [Tradución Ecléa Bosi e prólogo de Guilherme Almeida]. São Paulo, Editora Nós, Publicaçôes Galicia Ceibe.

Castro, Rosalía de (1979): Poesía. [Trad. Mauro Armiño, premio á mellor tradución]. Madrid, Alianza Editorial.

Castro, Rosalía de (1981): Cantares gallegos. [Ed. e trad. de Mauro Armiño. Texto paralelo en galego e tradución castelá]. Madrid, Akal.

CAstro, Rosalía de (1985): Follas novas=Hojas nuevas. [Trad. de Juan Barja con cronoloxía]. Madrid, Akal.

Castro, Rosalía de (1985): Cantares gallegos. [Trad. de Juan Barja]. Madrid, Akal.

Castro, Rosalía de (2002): Anthologie poétique. [Trad. José Carlos González. Nota biográfica de Robert Omnès]. Bedée, Folle Avoine / Rennes, Presses Universitaires de Rennes.

CAstro, Rosalía de (2009): Cantares gallegos. [Trad. Takekazu Asaka]. Tokyo, DTP Publishing.

Castro, Rosalía de (2009): Poesía completa de Rosalía de Castro. [Prólogo de Arturo Leyte]. Madrid, Abada Editores.

Castro, Rosalía de (2010): Follas novas. Reprodución de facsímiles da edición de Madrid, Impr. Aurelio J. Alaria de 1880. Bilingüe esp.-gal.

Castro, Rosalía de (2013): Galician Songs. [Trad. Erín Moure]. Sofía, Small Stations Press / [Santiago de Compostela], Xunta de Galicia.

FERNÁNDEZ RodrígueZ, Áurea (2012): «Un modelo metodológico pluridisciplinar. Nuevas herramientas nuevos enfoques», en Áurea Fernández Rodríguez / Ana Luna Alonso / Iolanda Galanes Santos / Silvia Montero Küpper, Traducción de una cultura emergente. La literatura gallega contemporánea en el exterior. 
Series: Relaciones literarias en el Ámbito Hispánico - Vol. 7, Bern / Berlín / Bruxelas / Frankfurt am Main / Nova York / Oxford / Wien, Peter Lang, 42-59.

Fernández Rodríguez, Áurea / Iolanda Galanes Santos / Ana Luna Alonso / Silvia Montero Küpper (2011): «A literatura galega en inglés. Unha realidade emerxente», Grial, 191:XLIX, 70-81.

Fernández Rodríguez, Áurea / Ana Luna Alonso / Iolanda Galanes Santos / Silvia Montero KüpPER (2012): Traducción de una cultura emergente. La literatura gallega contemporánea en el exterior. Series: Relaciones literarias en el Ámbito Hispánico - Vol. 7, Bern / Berlín / Bruxelas / Frankfurt am Main / Nova York / Oxford / Wien, Peter Lang.

Galanes Santos, Iolanda (2012): «La traducción literaria en Galicia a partir del catálogo BITRAGA», en Áurea Fernández Rodríguez / Ana Luna Alonso / Iolanda Galanes Santos / Silvia Montero Küpper, Traducción de una cultura emergente. La literatura gallega contemporánea en el exterior. Series: Relaciones literarias en el Ámbito Hispánico - Vol. 7, Bern / Berlín / Bruxelas / Frankfurt am Main / Nova York / Oxford / Wien, Peter Lang, 86-108.

Larra, Mariano (1981): Artículos, Barcelona, Planeta.

López, Aurora / Andrés Pociña (1991): Rosalía de Castro. Documentación biográfica y bibliografía crtítica (1837-1990). [Prólogo de Domingo García Sabell]. A Coruńa, Fundación Pedro Barrié de la Maza.

Luna Alonso, Ana (2012): «Traducir en nombre propio. De la Academia a la plaza pública», en Áurea Fernández Rodríguez: «Un modelo metodológico pluridisciplinar. Nuevas herramientas nuevos enfoques», en Áurea Fernández Rodríguez / Ana Luna Alonso / Iolanda Galanes Santos / Silvia Montero Küpper, Traducción de una cultura emergente. La literatura gallega contemporánea en el exterior. Series: Relaciones literarias en el Ámbito Hispánico - Vol. 7, Bern / Berlín / Bruxelas / Frankfurt am Main / Nova York / Oxford / Wien, Peter Lang, 149-176.

Montero Küpper, Silvia (2010): «Parámetros e funcionalidade do Catálogo de Tradución Galega», en Enric Gallén / Francisco Lafarga / Luis Pegenaute (eds.), Traducción y autotraducción entre las literaturas ibéricas, Berna, Peter Lang, vol. 2, 175-191.

Romero, Marga / Dieter Kremer (2007): 20 Gedichte aus Galicien, A Coruña, Espiral Maior.

Ruiz Aguilera, Ventura (1860): «La gaita gallega. Eco nacional. A mi querido amigo don Manuel Murguía», El Museo Universal, 48, ano IV, 25-XI-1860, 382-383.

Ruiz Aguilera, Ventura (1864): «Cantares Gallegos (conclusión)», El Museo Universal, 23, ano VIII, 5-VI1864, 182-183.

SÁnchez Romero, Antonio (1986): "Rosalía de Castro en Juan Ramón Jiménez», en Actas do Congreso internacional de estudios sobre Rosalía de Castro e o seu tempo, Santigo de Compostela, Consello da Cultura Galega / Universidade de Santiago de Compostela, III, 21 3-222.

Zernova, Elena (2008): «Antoloxía da literatura galega en ruso», A Trabe de Ouro, 74, 97-100.

Zernova, Elena (coord.) (1999): No limiar do novo milenio. Antoloxía da literatura galega. T. IV. [Limiar de Darío Villanueva]. San Petersburgo, Centro de Estudos Galegos da Universidade de San Petesburgo..

Zernova, Elena (ed.) (2000): Cancións da gaita. Poesía popular galega. T. V. [Limiar de Víctor Andreev]. San Petersburgo, Centro de Estudos Galegos da Universidade de San Petersburgo.

Zernova, Elena (ed.) (2005): Rosalía de Castro. [Limiar de Xesús Alonso Montero]. San Petersburgo, Centro de Estudos Galegos da Universidade de San Petersburgo. T. X. 
